\title{
THE CLINICAL PATHWAY IN THE ORAL AND MAXILLOFACIAL SURGERY'S SERVICES AS A QUALITY MANAGEMENT TOOL, IN DR. SOETOMO HOSPITAL, SURABAYA, INDONESIA
}

\author{
Nining Dwi Suti Ismawati ${ }^{1}{ }^{*}$ and Setya Haksam ${ }^{1}$ \\ ${ }^{I}$ Faculty of Public Health, Universitas Airlangga, Surabaya, Indonesia
}

\begin{abstract}
A Clinical Pathway is a comprehensive method of planning, delivering, and monitoring patient care. As efforts continue to streamline the delivery of services at all levels of care and settings, it is essential that quality management and utilization management professionals respond in a proactive manner to facilitate quality outcomes while decreasing cost and increasing efficiency. The aim of a Clinical Pathway is to enhance the quality of care across the continuum by improving risk-adjusted patient outcomes, promoting patient safety, increasing patient satisfaction, and optimizing the use of resources. However, there has not been any report on the implementation of the Clinical Pathway in Oral and Maxillofacial Surgery services in Indonesia. This research used observational methods and cross sectional design, with observational analysis and binary logistic regression. The population of this research was Clinical Pathway of Odontectomy were collected from medical records during January to December 2017 in ward surgery room of Dr. Soetomo hospital in Surabaya Indonesia. The Result obtained in this study, mostly completeness of Clinical Pathway were filled as the pattern. The amount of the sample in this research were $41 \mathrm{Clinical}$ Pathway, which $87,8 \%$ were fit according to the quality and cost indicator. The Variation in drug administration, treatment, and operator did not significantly influence (chi square $=0,93 ; \mathrm{df}=0 ; \mathrm{p}$ value $=1,00000$ )
\end{abstract}

Keywords: clinical pathway, clinical variation, continuous quality improvement, evidence-based medicine, health care processes, integrated care pathways

\section{Introduction}

Clinical Pathway(CP) also known as critical pathway critical pathway, care maps, integrated care pathway is an integrated management planning with the purpose of the patient's interest and provide sequence and exact time of action to achieve optimum effeciency (Panela et all, 2005, Every NR et all, 2000)

With the publication of the Indonesian Health Act No 242011 regarding about the Social Security Administration Agency or "Badan Penyelenggaraan Jaminan Sosial (BPJS)" where the rule states that the implementation of Health BPJS has to be done since the 25th of November 2012 and operational by the 1st of Januari 2014 and does not operate under the Ministry of Health, according to the Minister of Home Affairs Regulation article61 2007. ( Dody F, 2010)Dr. Soetomo Regional Public Hospital as a Regional Public Service Agency provides service to society based on the principal of effeciency and productivity prepares steps and strategies to carry out the Clinical Pathway for every diagnosis.( Nining D.S. Ismawati and Nugroho Setyawan, 2013)

Clinical Pathway as a service guideline in Soetomo hospital has been used since 2011 until now,( SK Direktur RSUD Soetomo, 2010, SK Direktur RSUD Soetomo, 2013) however there has been no report of research on the effectiveness and efficiency of clinical pathway at the service of Oral and Maxillofacial Surgery both in Indonesia and in International. 
The purpose of this study is to determine the clinical pathway used by the Oral and Maxillofacial Surgery Division in odontectomy service during 2017 as a tool for quality control and cost control. The benefit of this research is that it can be used as a clinical pathway audit material that is being used in the service guidance whether it is appropriate and effective in quality control and cost control so that improvement can be done to improve service quality.

\section{Method}

The type of this research is observational analytic research and cross sectional design, The population of this research was Clinical Pathway of Odontectomy were collected from medical records during January to December 2017 in ward surgery room of Dr. Soetomo hospital in Surabaya Indonesia.

The sample in this study is the entire population data ie the treatment of odontectomy with general anesthesia using clinical pathway in daily care in the room at the surgery ward which is treated by Oral and Maxillofacial Surgery Division from January to December 2017. We evaluate applying clinical pathways to process and outcome indicators, and to the costs sustained to assist the patient through the activity-based costing. This research uses technique non-probability sampling which is purposive sampling.

The data collection time of this study is estimated to take 2 weeks in June of 2018. The type of data used is secondary data, data processing is done with SPSS 20, the data is presented in the form of tables and drawings.Ethical clearance has been proposed with number 0459/124/VI/2018 as the cornerstone of research ethics that focused the hospital patients are subdued in patients in the hospital.A tool for evaluating clinical pathways using clinical pathway sheets of odontectomy procedures (surgical removal of embedded wisdom teeth).

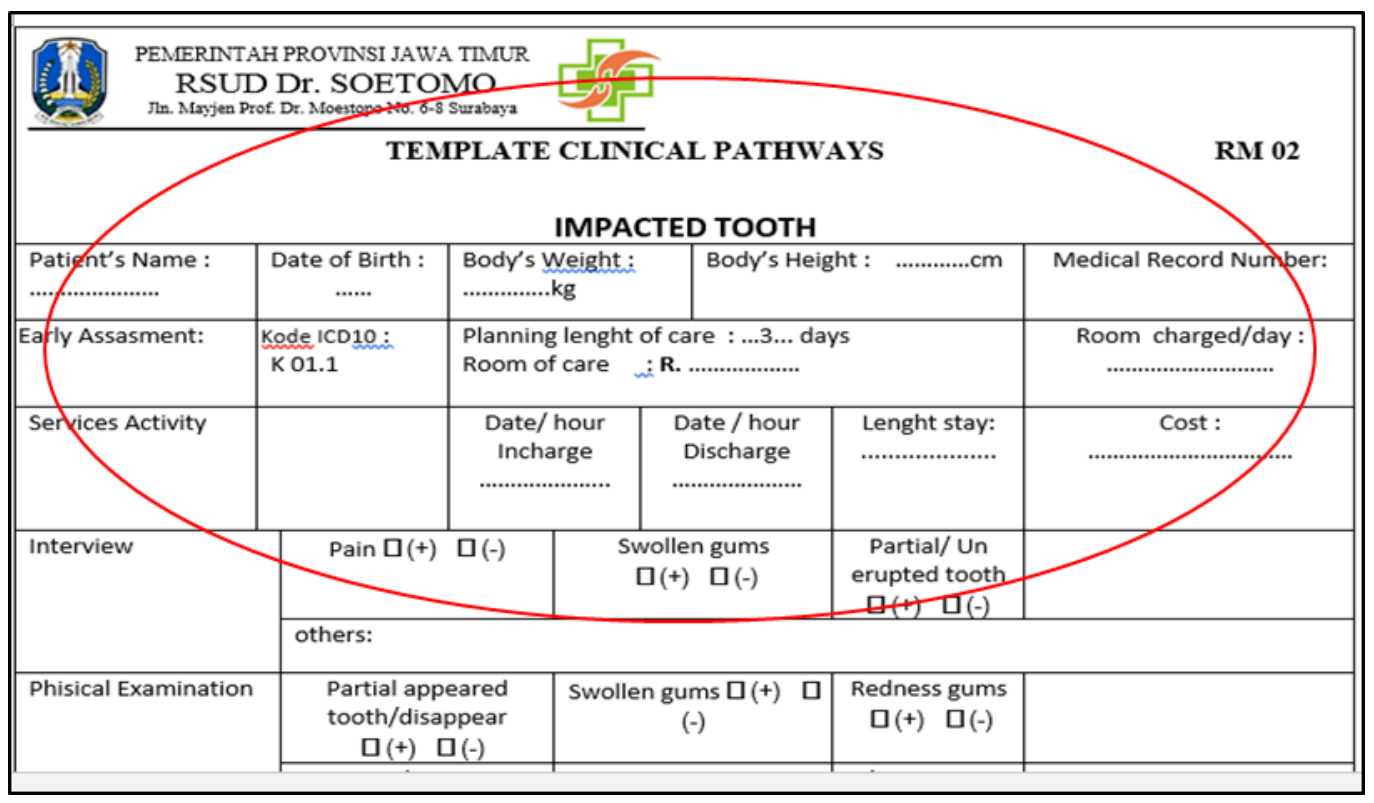

Figure 1: the current lenght of stay on odontectomy procedure 


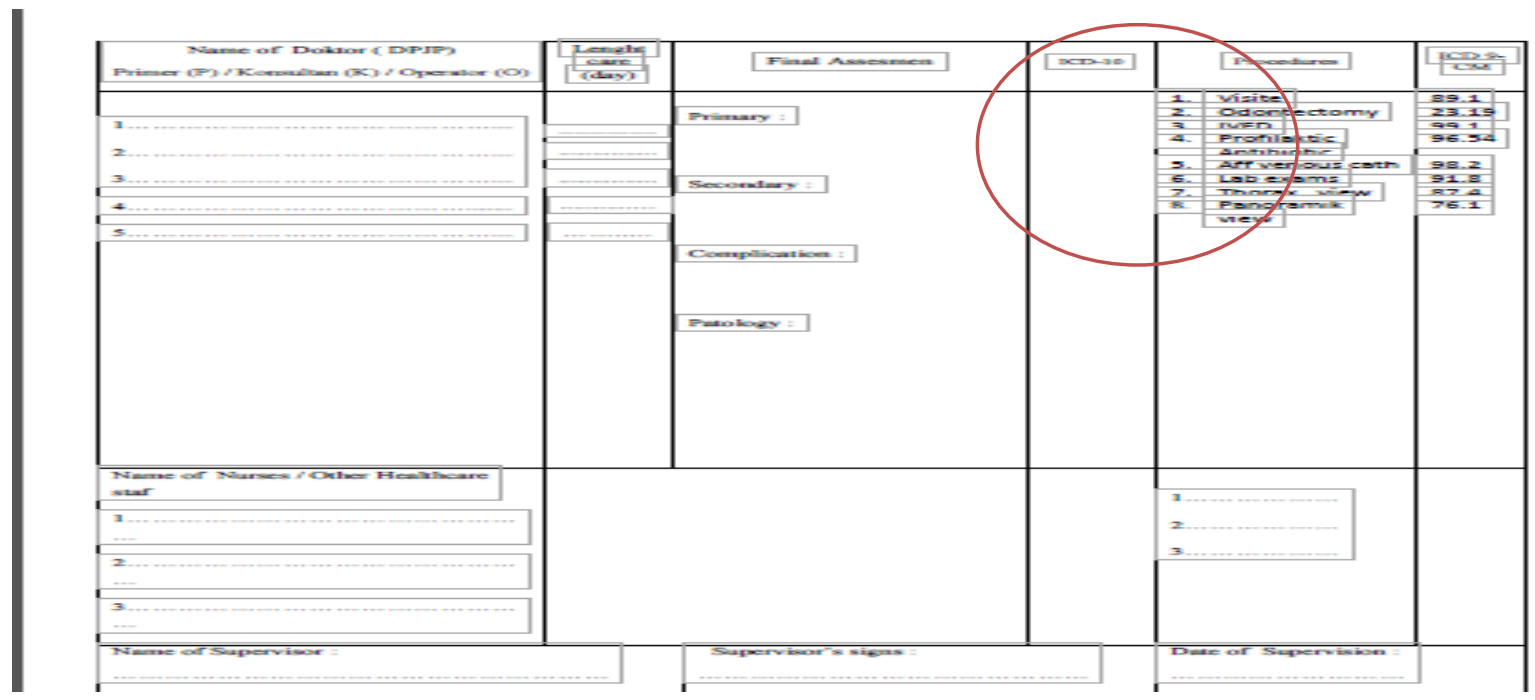

Figure 2: ICD of the procedure during treatment

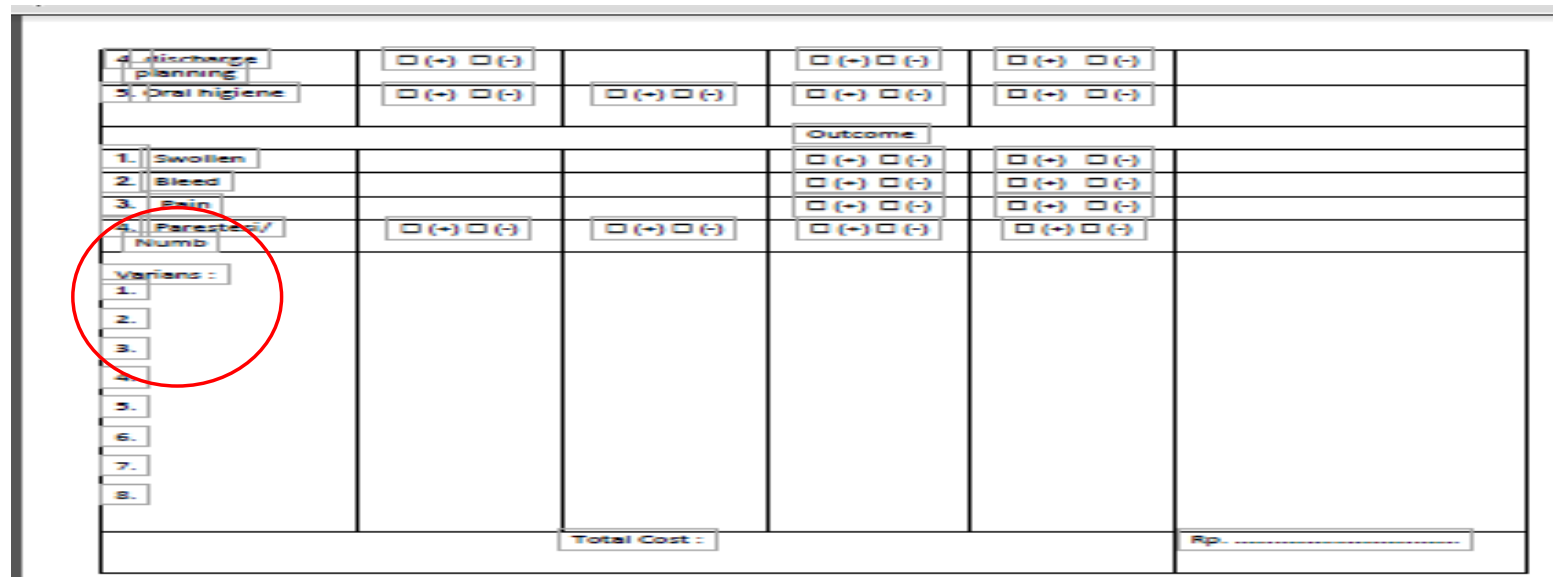

\section{Research Result}

From the evaluation and recording of the Clinical Pathway sheet during January to December 2017 it was found that the sheet was filled completely by a medical service provider according to the point / item that was loaded. From the observation, there were 41 clinical pathway samples with observation on variation: drug difference, length of hospitalization, operator change.

Table 1 Likelihood Ratio Test

\begin{tabular}{lllll}
\hline & Model Fitting Criteria & \multicolumn{3}{l}{ Likelihood Ratio Test } \\
\hline Effect & $-2 \log$ likelihood of Reduced Model & Chi - Square & Df & Sig \\
\hline Intercept & $9.274 \mathrm{a}$ & .000 & 0 &. \\
\hline Varobat & 13.938 & 4.664 & 2 & .097 \\
\hline Tindakan & $11.022 \mathrm{~b}$ & 1.748 & 4 & .782 \\
\hline Operator & $10.634 \mathrm{~b}$ & 1.360 & 2 & .507 \\
\hline
\end{tabular}

In the likelihood ratio of the table, the observed variables were the type of drug, the type of action and the difference of the operator. 
Tabel 2 Model Fitting Information

\begin{tabular}{lllll}
\hline & $\begin{array}{l}\text { Model Fitting Criteria -2 Log } \\
\text { likelihood }\end{array}$ & \multicolumn{3}{l}{ Likelihood Ratio Tests } \\
\hline Model & & Chi Square & Df & Sig. \\
\hline Intercept Only & 17.696 & & & \\
\hline Final & 9.274 & 8.422 & 8 & .393 \\
\hline
\end{tabular}

In the table above obtained sig figure is 0.393 greater than the value of $\mathrm{p}(0.05)$

\section{Discussion}

From the results of research on 41 clinical pathway odontectomy in the oral and maxillofacial surgery division at Dr. Soetomo hospital Surabaya which is the total population of clinical pathway odontectomy procedure, meaning no samples that dropped out.

The result of statistical calculation with binary logistic regression found significance value equal to 0,393 which is bigger than $\mathrm{p}$ value $<0,05$, which can be interpreted that the variable measured have a meaningful influence to its dependent variable that is length of hospitalization. The length of hospitalization is used as a measure / indicator of service quality where with the assured quality of service, the length of treatment can be controlled according to the therapy guidelines. The length of hospitalization in addition to reflecting the quality of service can also be used as a tool for the control of patient care costs in hospitals. ( Yangga D Nur and Setya Haksama, 2016)

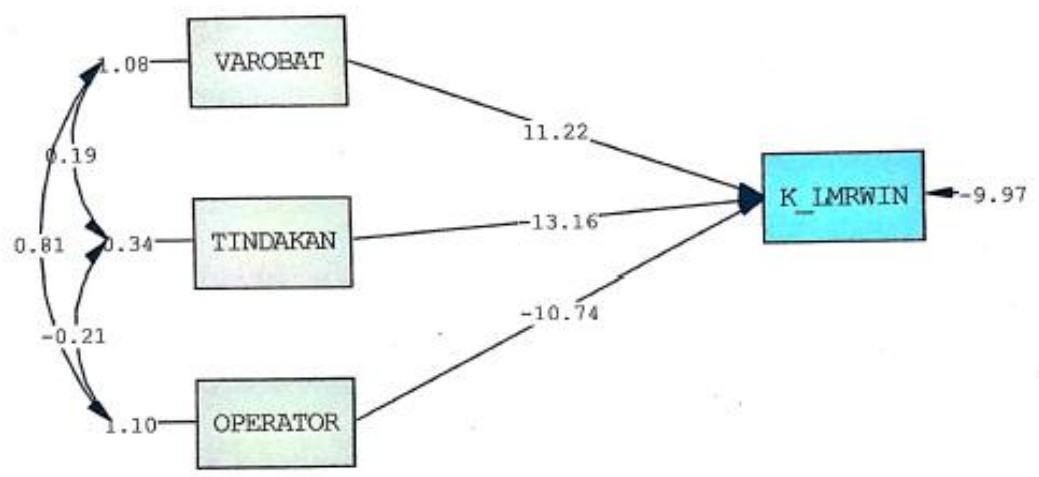

Figure 4: Path analysis

Quadratic number obtained from each variable on length of stay: the influence of the number of actions on length of hospitalization $=13,16$; type of drug $=11.22$; operator difference $=-10.74$. Medium between vriable independent against one another is small

In the path analysis of each variable shows the effect on the length of hospitalization. In the clinical pathway has been determined all items / points to be done both examination, treatment and action, including the type of drug to be given. If there is a discrepancy with the items on the clinical pathway sheets are allowed if there are exceptions due to the patient's special condition, collision on administrative difficulties and the number of human resources. However, on path analysis of clinical pathway data of oral and maxillofacial surgery showed that all of these variables did not affect the duration of hospitalization, where variation of drug type resulted in $11.22(1.25 \%)$ variation of action of $13.16(1.73 \%)$ and operator variation of $-10.74(1.15 \%)$ where chi square is $0.93, \mathrm{df}=0$ and $\mathrm{p}=$ value $=1,00000$ 


\section{Conclusion}

Clinical Pathway samples studied were 41 cases, with observed procedures being odontectomy, with observed variables being drug type, operator variation, and variation in the number of measures. From the calculation of statistical analysis of binary logistic regression, it is found that the variation of three variables is not significant to the length of hospitalization.

\section{References}

DodyFirmanda, dr., sp.A., MA., RSUP Fatmawati, Jakarta. 2010., Mutupelayananmedisdengankepastianbiaya. http://www.scribd.com/Komite Medik.

Panela, Massimilano., Maxwell asia. 2005. Essential of Medical Law., Singapore Journal of medical studies. P.471-3.

SK DirekturRumahsakitUmum dan Pendidikan Dr. Soetomosurabayanomor 188.4/7252/301/2010 tentang Clinical Pathway.

SK DirekturRumahsakitUmum dan Pendidikan Dr. Soetomosurabayanomor 188.4/2989/301/SK/2013 tentang Audit Medis Clinical Pathwaydan PPK

Every NR, Hochman J, Becker R, Lopecky S, Cannon CP. Critical pathways. A review. Circulation ,2000, 5

Nining D.S.Ismawati , Nugroho Setyawan. The Clinical Pathway in The Oral and Maksillofacial Surgery's services as a Quality Management Tool, in Dr. Soetomo General and Teaching Hospital, Surabaya, Indonesia : A Review Article, science meeting of Oral maxillofacial , 2013, Malang, Indonesia.

Yangga D Nur and Setya Haksama. Inpatient Performance Assesment Based on Balanced Score Card , Jurnal Administrasi Kesehatan Indonesia Volume 4 Nomor 1 Jan-June 2016 